\title{
$\begin{array}{ll}\text { Research Square } & \text { Preprints are preliminary reports that have not undergone peer review. } \\ \text { They should not be considered conclusive, used to inform clinical practice, } \\ \text { or referenced by the media as validated information. }\end{array}$
}

\section{Chinese Younger Parents' Quality of Life during COVID-19 Pandemic: Do Job Changes and Family Conflicts Matter?}

\author{
Xiaohan Liu \\ Peking University \\ YaShuang Bai \\ Peking University \\ Ning Huang \\ Peking University \\ JING GUO ( $\sim$ jing624218@163.com ) \\ Peking University https://orcid.org/0000-0001-8085-0117
}

\section{Research}

Keywords: Quality of Life, Job Changes, Family conflict, Chinese Parents

Posted Date: August 17th, 2021

DOI: https://doi.org/10.21203/rs.3.rs-786645/v1

License: (1) This work is licensed under a Creative Commons Attribution 4.0 International License. Read Full License

Version of Record: A version of this preprint was published at Frontiers in Public Health on January 21st, 2022. See the published version at https://doi.org/10.3389/fpubh.2021.758242. 


\section{Abstract}

Background囚The quality of life might have been decreased owing to the social disruptionsin daily life and basic functioning afterCoronavirus Disease (COVID-19) pandemic. This study aims to examine the relationship between job changes, family conflicts, and quality of life among parents during COVID-19 in China.

Methods『We recruited 1209 adultsthrough an online cross-sectional survey in China during the COVID-19 lockdown from April $21^{\text {st }}$ to April $28^{\text {th }}, 2020$.Convenient and cluster sampling methods were used to recruit parents. The global health items in the PatientReported Outcomes Measurement Information System (PROMIS) were used as a measurement forquality of life. Data were mainly analyzed by multiple linear regression with SPSS.

Results $₫$ Both marital conflict $(\boldsymbol{\beta}=-0.243, \mathrm{P}<.001)$ and parent-child conflict $(\boldsymbol{\beta}=-0.119, \mathrm{P}=.001)$ were negatively associated with the quality of life among parents during the lockdown. While job changes moderatedthe relationship of marital conflict and quality of life $(\boldsymbol{\beta}=-0.256, P=.022)$. Besides, the interaction effects of job changesand family conflict on quality of life only significantly amongfathers andone child families.

Conclusion区This study indicated the familyconflictwas acrucialfactorcorrelatedwithqualityoflifeamongyoungparents in the backdrop of COVID-19 lockdown. Job changes could interact with marital conflict and parent-child conflict on quality of life.

\section{Background}

The coronavirus disease 19 (COVID-19), which emerged in Wuhan, China, has reached the level of a pandemic, attracting enormous concern from around the world [1]. Several countries took drastic mitigation measures, including community-wide lockdowns, home quarantines, closure of schools, working-from-home, and social distancing to protect the population [2]. However, these swift actions have created a host of new challenges that have brought profound changes and affected the normal routines of daily work and lifestyles for people, such as restricting outdoor activities or increasing family conflicts, reducing income, high rates of unemployment[3], and consequently, worsening the quality of life (QoL) [4].

Quality of life is a multidimensional concept that usually includes individuals' physical health, psychological state, and level of independence et al [5]. Widespread outbreaks of COVID-19 may adversely affect the multidimensional quality of life, especially in parents who have children below 10 years old. Emerging research has shown that parents of young children would be more affected by the COVID-19 pandemic [6], since young children need more supervision and care, and then the pandemic may bring the unique challenge to parents of young children[7]. Specifically, parents with young children may have more childcare responsibilities at home due to the reduced social network, and the swift closure of school and childcare-center[7]. Besides, they had to balance remote working with home-schooling their children and confront more work-family conflict [8]. Thus, in this difficult time, more attention is required to the younger parents' quality of life.

\section{Job changes and Quality of Life}

Job changes are significant life stressors, and losing a job takes several years to recover psychologically [9]. According to the family stress model [10], economic instability (including unemployment, debt, and receipt of income transfers) places considerable strain on parents. The COVID-19 pandemic has forced parents to quickly transition to a new way of work [11]. These transitions present all kinds of stressors, which might have repercussions on parents' capacities to be psychologically flexible, thus putting their quality of life at risk [11].

\section{Family conflict and Quality of Life}

An active opposition of various forms including verbal, physical, sexual, financial, or psychological among family members is often referred to as family conflict [12]. According to the adult attachment theory, high-quality close relationships, including marital relationship and parent-child relationship, have been consistently linked to better health, while conflict relationship may influence parent's physiological responses to stress, risky health behaviors, susceptibility to physical illness, and poorer disease outcomes [13]. When parents were asked to stay at home during the pandemic, they faced problems getting along with their family members and dealing with the conflicts with their partner and children. There is evidence that a close relationship between family members 
could affect the parents' quality of life, and parents' health status can further affect children's development and well-being, creating a vicious circle in such a difficult period $[14,15]$.

\section{Conceptual framework}

Theories and empirical results based on role stress theory indicate that the combination of family and employment often creates more demands than one can handle-leading to role overload [16]. Consequently, both job changes and family conflict can bring more stress and psychological problems for parents of young children.

The interaction effect of job changes and family conflicts on quality of life may be different for mothers, and fathers. COVID-19 has indeed changed parents' experiences with employment outside the household and the division of labor at home [17]. Compared to fathers, mothers have reduced their working hours more, and spent more time on childcare duties [18]. Moreover, school and daycare closures increased caregiving responsibilities. Arguably, these changes increased the burden on women more than on men [19]. Therefore, this study anticipates that mothers have experienced more job changes, perceived more family conflicts, and low quality of life than fathers.

Additionally, the interaction role between job changes and family conflict on quality of life may differentiate across the number of children. The traditional belief, "more children, more happiness," is still entrenched in China [20]. Evidence has shown that parents could obtain more emotional support from their children in the multi-children family [21], and parents with more children perceive a higher level of life satisfaction. Besides, parents tend to rear more children if they could easily integrate work and family roles to reduce the double burden. [22]. Thus, the association between family conflict and quality of life in the multi-children family may not be enhanced by job changes.

\section{Aims and hypothesis}

The objective of this study was to examine the relationship between job changes, family conflict, and quality of life among parents with a child aged $0-10$, to assess the interaction effects between job changes and family conflict, and to explore the difference of gender and family size among them. We hypothesized that either job changes or family conflicts correlated with parents' poor quality of life. We further hypothesized that the pandemic related job changes enhanced the relationship between family conflict and poor quality of life. Moreover, we assumed that the above-mentioned moderating effects were varied across gender, and families with different number of children.

\section{Methods}

\section{Study design and population}

This study was conducted based on an online survey (a web-based platform, https://www.wjx.cn/app/survey.aspx) from April 21st to April 28th, 2020, during the COVID-19 lockdown in China. In order to nationally reflect the mental health status of parents affected by pandemic and enlarge the sample size, Hubei province, the most affected areas by COVID-19, and its neighboring province Henan and non-adjacent province Guangdong were selected for sample investigation.

Convenient and cluster sampling methods were used to recruit parents of children below 10 years old. Convenience sampling is used to select primary schools. The cluster sampling method was used to choose participants from selected schools. The selected schools were stratified by grade. Then, all classes were selected from each grade of the selected school and all of the students in these classes joined the survey. The head teachers helped us distribute the questionnaires to the subjects online.

Parents aged 18 years and above, who had a child or children aged between 0 and 10 years old were invited to participate. The rationale for restricting the sample to parents with at least one child 10-years-old or younger was that younger children necessitate more direct supervision; therefore, it was expected that the covid-19 pandemic may take more specific challenge to them, like more work-family conflict. These parents were instructed about how to answer the questionnaires by the online guidance and completed the questionnaires independently. In total, 1286 parents participated in the survey. As 77 parents were excluded because they had no job, the final number of participants became 1209. Each question of online questionnaire was required to be answered, thus no missing data reported in our study. The study protocol was approved by the Institutional Review Board of Peking University, Beijing, 
China. All participants gave electronic consent after being informed to the aims of the survey and their rights to refuse to participate.

\section{Measures}

Quality of life was assessed with the global health items in the Patient-Reported Outcomes Measurement Information System (PROMIS) [23]. The checklist includes 6 items, which were answered on a five-point scale, Excellent(1)-Poor(5). See the attachment for details. The total scores were calculated by the sum of all items; with a higher score indicative of the better the quality of life. Cronbach's alpha of quality of life in this study was 0.916 .

Job changes were assessed with a subset of items from the questionnaire of the Covid-19 and Perinatal Experiences Study (COPE Study,https://osf.io/uqhcv/). The scale contained 15 questions about the changes in jobs related to the COVID-19 pandemic, such as telecommuting, reduced working hours, extended working hours, pay cuts, increased responsibility, increased supervision and reporting, declining job security et al. For each question, 0 represented 'No,' while 1 represents 'Yes.' All items were summed to obtain a total score for job changes. A higher score represented more job changes. The internal consistency of job changes was 0.881 .

Family conflict was measured with a 6-item self-made questionnaire about the specific conflict behaviors including marital conflict and parent-child conflict. Among them, three questions examining marital conflict and other three items about parent-child conflict Each item was rated on a five-point scale ranging from never ( 1 score) to always ( 5 scores). For details, please page to attachment. Higher scores indicated more frequent marital and parent-child conflict. The Cronbach's a were 0.696 and 0.726 , respectively. The questionnaire items were vetted by some of sociological professors and they agreed that there were no items that were culturally insensitive.

Confounding variables included demographic and socioeconomic characteristics as following: exposure to COVID-19 (yes, no), gender (male, female), province (Hubei, Henan, Guangdong, else), number of children (1, 2, 3 or more), education (junior school and below, high school, college, undergraduate and above), marital status (married, else), occupation (stable, unstable), and annual income ( $\leq 50000,50000-100000, \geq 100000$ ). In the study, this term (stable job) we mean work that is a continuous and safe employment, there is no sudden layoffs or labor strife. Unstable jobs we mean work that is uncertain, insecure, irregular and in which employees bear the risks of work and receive limited social benefits, relatively low income and statutory protections. (i.e. In China, employees work in state-owned enterprises and public institutions are regarded having the stable job. Unstable job employees refer to free-lancer and gig workers). All covariates were selected according to previous related studies [24, 25].

\section{Statistical analyses}

Data in this study were analyzed with the SPSS version 22.0. Descriptive statistics were calculated to describe the demographic characteristics of the subjects.

The main analyses consisted of multiple regressions on quality of life in two steps. In model 0 each of the predictors was included separately to estimate their 'raw' contribution to the prediction of quality of life, and in model 1 the three predictors of job changes, marital conflict, and parent-child conflict were introduced to examine which component would be the most powerful predictor.

In the next multivariable linear regression analysis, job changes, marital conflict and parent-child conflict and their interaction terms (job changes*marital conflict and job changes*parent-child conflict) were all standardized and entered, to estimate the moderating effects of job changes on the relationships between marital conflict, parent-child conflict, and quality of life.

In addition, the whole sample was divided into 2 groups by gender to examine gender differences in the moderating effects of job changes on the relationships between marital conflict, parent-child conflict, and quality of life. In the final linear regression models, the whole sample was divided into 3 groups by the number of children in a family.

\section{Results}

Socio-demographic characteristics of the study are presented in Table 1. Of the total 1209 surveyed participants, $73.8 \%$ of the parents were mothers. Nearly $21.2 \%$ were from Hubei. In terms of the number of children, $47.2 \%$ of the parents had one child. Concerning exposure to COVID-19, 18.7\% reported that someone in their family, neighborhood, and friends had suffered or suffering 
from COVID-19. 6.9\% parents did not experience any job changes. The average number of job changes is 17.85 . Most people experienced family conflict $(97.7 \%)$. The mean score of QoL was $23.85(S D=3.60)$.

Table 1

Descriptive data on social-demographics ( $N=1209)$

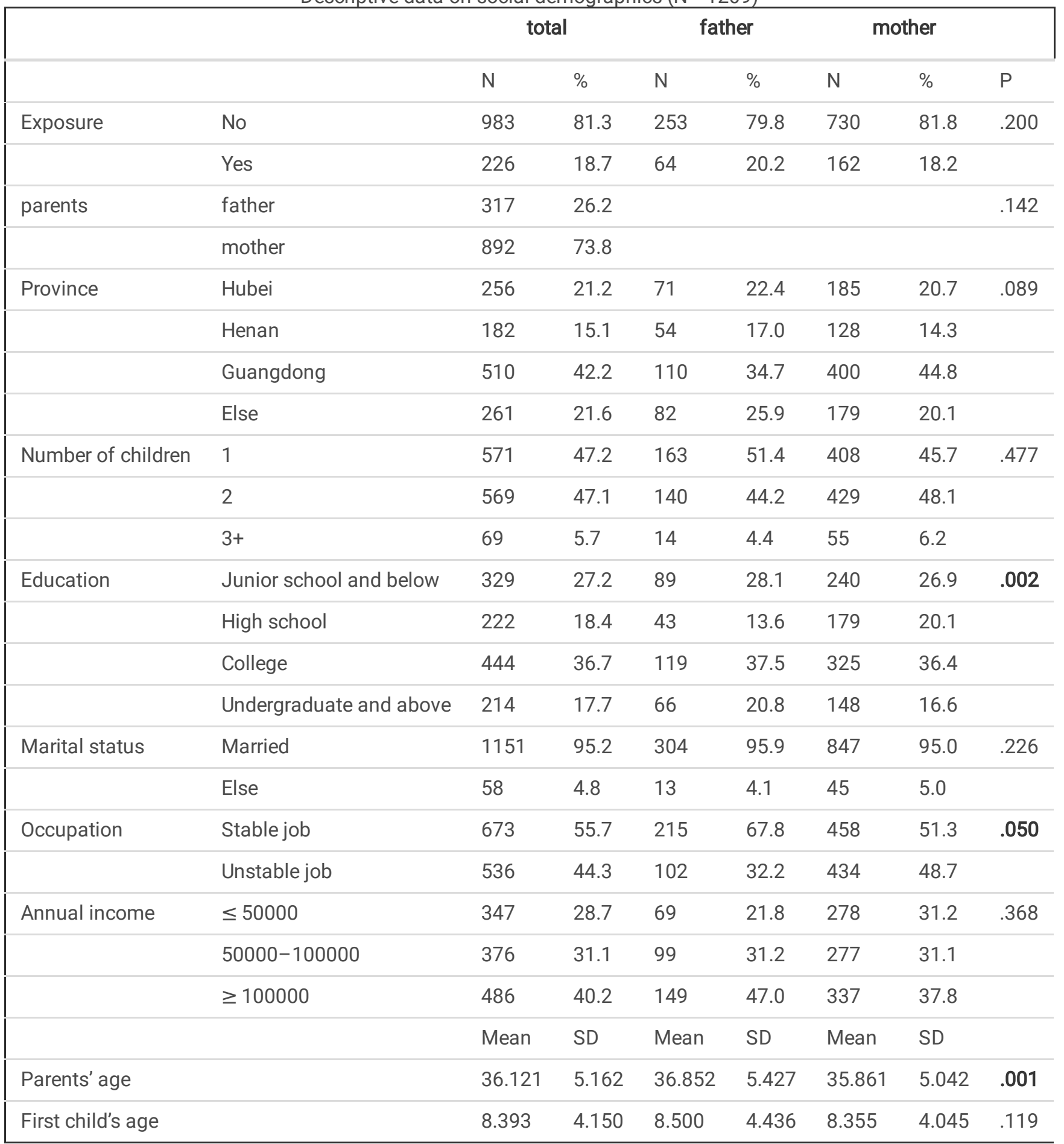

Table 2 shows the results of the multivariable linear regression analysis. In model 0 , job changes, marital conflict, and parent-child conflict were all significantly associated with quality of life. In model 1 , marital conflict explained the largest variance in quality of life. More marital conflict was associated with lower quality of life $(\beta=-0.243)$. Also, parent-child conflict was negatively significantly correlated with quality of life $(\beta=-0.441, P=.001)$. However, Job changes did not significantly relate to the quality of life in model 1. 
Table 2

The relationship between job changes, family conflicts and quality of life.

\begin{tabular}{|c|c|c|c|c|c|c|c|c|}
\hline & \multicolumn{4}{|c|}{ Model 0} & \multicolumn{4}{|c|}{ Model 1} \\
\hline & B & SE & Beta & $P$ & $\mathrm{~B}$ & SE & Beta & $P$ \\
\hline \multicolumn{9}{|l|}{ Parents (ref: father) } \\
\hline mother & -0.370 & 0.244 & -0.045 & .130 & -0.039 & 0.233 & -0.005 & .866 \\
\hline \multicolumn{9}{|c|}{ Number of children(ref: $3+$ ) } \\
\hline 1 & 0.319 & 0.486 & 0.044 & .512 & 0.332 & 0.464 & 0.046 & .475 \\
\hline 2 & 0.006 & 0.470 & 0.001 & .989 & -0.005 & 0.446 & -0.001 & .990 \\
\hline Job changes & -0.258 & 0.109 & -0.071 & .019 & -0.076 & 0.105 & -0.021 & .473 \\
\hline Marital conflict & -0.899 & 0.131 & -0.241 & $<.001$ & -0.905 & 0.133 & -0.243 & $<.001$ \\
\hline Parent-child conflict & -0.464 & 0.131 & -0.125 & $<.001$ & -0.441 & 0.133 & -0.119 & .001 \\
\hline \multicolumn{9}{|c|}{$\begin{array}{l}\text { Notes: B: Non-standardized coefficients; SE: standard error, Beta: Standardized coefficients; bold values are statistically } \\
\text { significant at } \mathrm{p}<0.05 ; \text { Model } 0 \text { is crude estimates and Model } 1 \text { is the estimates accounting for all three independent variables } \\
\text { (job changes, marital conflict, and parent-child conflict). All models have been controlled exposure, province, age, education, } \\
\text { marital status, income, occupation, first child age. }\end{array}$} \\
\hline
\end{tabular}

The interaction effects of job changes with family conflict were presented in Table 3 . Model 2 revealed the job changes significantly moderated the relationship between marital conflict and quality of life $(\beta=-0.256, P=.022)$. As shown in Fig. 1-A, parents who reported more changes in work and had experienced marital conflict showed a lower level of quality of life. But the interaction of job changes and parent-child conflict was not significant.

Table 3

Interaction effects analysis between job changes and family conflicts on quality of life.

\begin{tabular}{|c|c|c|c|c|}
\hline & \multicolumn{4}{|c|}{ Model 2} \\
\hline & B & SE & Beta & $\mathrm{P}$ \\
\hline \multicolumn{5}{|l|}{ Parents (ref: father) } \\
\hline mother & -0.067 & 0.234 & -0.008 & .775 \\
\hline \multicolumn{5}{|l|}{ Number of children(ref: $3+$ ) } \\
\hline 1 & 0.334 & 0.463 & 0.046 & .470 \\
\hline 2 & -0.012 & 0.446 & -0.002 & .979 \\
\hline Job changes & -0.071 & 0.105 & -0.020 & .498 \\
\hline Marital conflict & -0.824 & 0.137 & -0.221 & $<.001$ \\
\hline Parent-child conflict & -0.497 & 0.135 & -0.134 & $<.001$ \\
\hline Job changes* marital conflict & -0.256 & 0.111 & -0.077 & .022 \\
\hline Job changes*parent-child conflict & 0.219 & 0.124 & 0.058 & .077 \\
\hline
\end{tabular}

Table 4 displays gender differences in the interaction roles between job changes and family conflict. The interaction effects of job changes with marital conflict $(\beta=-0.421, P=.024)$ and parent-child conflict $(\beta=0.747, P=.002)$ were only found for fathers, indicating that job changes reinforced the negative effect of marital conflict while the alleviated adverse effect of parent-child conflict on the quality of life among fathers (See Fig. 1-C and Fig. 1-D). Table 5 presents the interaction results of job changes with family conflict across families with a different number of children. Only in the one-child family were the moderation effects of job 
changes with marital conflict and parent-child conflict found $(\beta=-0.304, P=.024$ and $\beta=0.412, P=.011$, respectively). As presented in Fig. 1-E and Fig. 1-F, the negative effect of marital conflict on quality of life could be strengthened by job changes among parents with one child, whereas the adverse correlation between parent-child conflict and quality of life would be weakened.

Table 4

Interaction effects analysis between job changes and family conflicts on quality of life in gender subgroup.

\begin{tabular}{|c|c|c|c|c|c|c|c|c|}
\hline & \multicolumn{4}{|c|}{ Model 3: father } & \multicolumn{3}{|c|}{ Model 4: mother } & \multirow[b]{2}{*}{$P$} \\
\hline & B & SE & Beta & $P$ & B & SE & Beta & \\
\hline \multicolumn{9}{|l|}{ Number of children(ref: $3+$ ) } \\
\hline 1 & 0.889 & 1.008 & 0.120 & .378 & 0.172 & 0.522 & 0.024 & .741 \\
\hline 2 & 0.320 & 0.992 & 0.043 & .747 & -0.002 & 0.500 & 0.000 & .997 \\
\hline Job changes & -0.124 & 0.217 & -0.034 & .568 & 0.003 & 0.123 & 0.001 & .980 \\
\hline Marital conflict & -1.354 & 0.344 & -0.326 & $<.001$ & -0.672 & 0.151 & -0.186 & $<.001$ \\
\hline Parent-child conflict & 0.002 & 0.315 & 0.000 & .996 & -0.653 & 0.151 & -0.181 & $<.001$ \\
\hline Job changes * marital conflict & -0.421 & 0.186 & -0.153 & .024 & 0.005 & 0.151 & 0.001 & .974 \\
\hline Job changes *parent-child conflict & 0.747 & 0.242 & 0.188 & .002 & -0.091 & 0.152 & -0.025 & .550 \\
\hline \multicolumn{9}{|c|}{$\begin{array}{l}\text { Notes: B: Non-standardized coefficients; SE: standard error, Beta: Standardized coefficients; bold values are statistically } \\
\text { significant at p<.05; All models have been controlled exposure, province, age, education, marital status, income, occupation } \\
\text { first child age. }\end{array}$} \\
\hline
\end{tabular}

Table 5

Interaction effects analysis between job changes and family conflicts on quality of life in number of children subgroup.

\begin{tabular}{|c|c|c|c|c|c|c|c|c|c|c|c|c|}
\hline & \multicolumn{4}{|c|}{ Model 5: one child family } & \multicolumn{4}{|c|}{ Model 6: two children family } & \multicolumn{4}{|c|}{$\begin{array}{l}\text { Model 7: multiple children family } \\
(3+)\end{array}$} \\
\hline & B & SE & Beta & $P$ & B & SE & Beta & $P$ & B & SE & Beta & $\mathrm{P}$ \\
\hline \multicolumn{13}{|l|}{$\begin{array}{l}\text { parents(ref: } \\
\text { father) }\end{array}$} \\
\hline mother & -0.306 & 0.317 & -0.039 & .334 & 0.235 & 0.372 & 0.028 & .529 & 1.852 & 1.310 & 0.199 & .164 \\
\hline Changes in job & 0.075 & 0.162 & 0.020 & .643 & -0.073 & 0.156 & -0.020 & .640 & -0.331 & 0.453 & -0.108 & .469 \\
\hline Marital conflict & -0.857 & 0.183 & -0.254 & $<.001$ & -0.738 & 0.219 & -0.180 & .001 & -1.001 & 1.162 & -0.219 & .393 \\
\hline $\begin{array}{l}\text { Parent-child } \\
\text { conflict }\end{array}$ & -0.439 & 0.189 & -0.121 & .021 & -0.655 & 0.207 & -0.171 & .002 & -0.411 & 0.916 & -0.116 & .655 \\
\hline $\begin{array}{l}\text { Job changes* } \\
\text { marital conflict }\end{array}$ & -0.304 & 0.135 & -0.106 & .024 & -0.250 & 0.225 & -0.063 & .266 & 1.230 & 0.902 & 0.335 & .179 \\
\hline $\begin{array}{l}\text { Job } \\
\text { changes*parent- } \\
\text { child conflict }\end{array}$ & 0.412 & 0.161 & 0.115 & .011 & -0.017 & 0.228 & -0.004 & .940 & -0.395 & 0.639 & -0.127 & .539 \\
\hline $\begin{array}{l}\text { Notes: B: Non-stan } \\
\text { significant at } p<.0 \\
\text { first child age. }\end{array}$ & Irdized & efficie & SE: st & dard err & ; Beta: & indard & d coeff & ents; & d valu & re st & $\begin{array}{l}\text { tically } \\
\text { ccupat }\end{array}$ & \\
\hline
\end{tabular}

\section{Discussion}

The present study focused on the quality of life among Chinese parents of young children during the COVID-19 pandemic and examined the relationship between job changes, family conflict, and quality of life. Our findings suggested that individuals with 
more frequent marital conflict and parent-child conflict had worse quality of life. And we found that job changes significantly enhanced the negative correlation between marital conflict and quality of life, but not significantly buffered the negative relationship between parent-child conflict and quality of life among whole sample. Besides, both of the moderation effects differed across gender and family structure, and they were only significant for fathers and one child family.

Our results indicated that parents who experienced marital conflict and parent-child conflict reported a lower level of quality of life. Marital conflict may decrease the marital quality of life through increasing negative affect and physiological arousal, according to social psychophysiological model of marriage [26]. Besides, stress process perspectives proposed that chronic strains in the marital role could cause stress, which typically manifested in the physical or psychological distress form, as indicated by the poor quality of life [27]. Similarly, parent-child conflict might be regarded as a chronic stressor or stressful life event, that influences parents' mental health [28]. And empirical research demonstrated that parents in families with a high level of parent-child conflict might more possibly suffer depressive symptoms [29], which may reduce parental quality of life.

Furthermore, job changes did act as a moderator between family conflict and quality of life. On the one hand, job changes accelerated the negative effect of marital conflict on quality of life. It could be explained by the family stress theory [30], the financial stress coming with job change as an uppermost topic of marital disagreements could cause more emotional distress and then heighten marital conflict [31]. Moreover, role theory argues that the role pressures from family and work domains are mutually incompatible in some respects, and job stress would negatively spill over into home life [32], which may cause increased conflicts with spouses. Thus, when facing job changes, individuals who suffered from marital conflict may perceive lower quality of life.

On the other hand, job changes could moderate the negative correlation between parent-child conflict and quality of life. Since some special features of the job changes during the COVID-19, such as the flexible work time, telework and working from home, could make these parents have more time to accompany with their children at home, and thus improving the relationship between parents and children [33]. It is also helpful to meet the expectations of parental roles like caring for children, especially for young Chinese parents who always experienced overtime work with less time to interact with family members [34]. Therefore, the job changes could mitigate the negative effect of parent-child conflict on parents' quality of life. Given that the impacts of the COVID-19 pandemic on the economy, work and home life are manifold and will potentially last for a long time [35], understanding such interactions will be important to provide service for improvement of quality of life among parents.

Of note, the moderating role of job changes was confirmed only for Chinese fathers. Since traditional gender values that "fathers are regarded as the primary breadwinners and mothers as primary caregivers" are still the most far-reaching and prevalent in China [36], work factors would spill over into family more for Chinese men than women, based on gender role theory [37]. Specifically, the financial loss coming with job changes during the pandemic may more likely make Chinese husbands as family economic pillars feel stressed than their wives [38], and thus enhancing the negative relationship of marital conflict and quality of life among fathers. And the job changes more likely increase positive interactions with children for fathers like playing games which could improve the father-child relationship[39, 40], and thus weakening the association between parent-child conflict and father's quality of life.

In addition, job changes only moderated the association between family conflict and parents' quality of life in the one-child family. It could be explained using resource dilution theory [41], children in the one-child family could get more attention and resource from parents [42], which means parents with only child can more easily meet their children's demands using job resources from job changes than parents with multi-children. [43]. So, job changes could only buffer the adverse effect of parent-child conflict in onechild families.

Moreover, the association between marital conflict and quality of life could only be enhanced by job changes in the one-child family. This is because parents with fewer children in collectivistic cultures may have lower marital happiness [44]. Besides, previous research examined the quality-quantity trade-off theory based on the relaxation of China's one-child policy [45]. It suggested that Chinese parents with one child might have a strong preference for quality and devote more time, energy, and money to their children's development than other parents [46]. Therefore, extended working hours, pay cuts or unemployment would increase more child-rearing pressure on parents with an only child, while the pressure could be mitigated in the multi-children family owing to more support and assistance from children [19]. 


\section{Limitation And Implication}

Several limitations of this study should be acknowledged. First the selective bias resulted from convenient sampling methods used in our study might constrain the generalizability of our findings. Second, the proportion of fathers is less than $30 \%$ in our study, which may suggest we may miss the data from fathers who are quietly busy with their job or others things. Thus, we should be cautious to generalize our results. Third, our study only included limited job changes forms without consulting the vocational psychology, that may fail to fully reflect the relationship between job changes and young parents' QoL. Fifth, with the crosssectional design of the current research, it's difficult to make a causal inference. Longitudinal designs are expected in future studies to help clarify the causal relationships.

Despite these limitations, the findings of this study have significant implications. First, the QoL among young parents experiencing job changes and family conflict should be given adequate attention during the COVID-19 confinement, and corresponding proactive and applicable interventions can be proposed. For example, community organizations and social workers should pay more attention to the prevention of family conflict. Besides, fathers and one-child families need to implement psychological interventions (that mitigate the marital conflict) and work insurances (that reduce the financial pressure).

\section{Conclusion}

This study indicates that family conflict is an important factor related to the quality of life among Chinese younger parents. Job changes are found to moderate the association between family conflict and quality of life. Besides, we find these interaction effects differ across gender and family structure, and they are only significant for fathers and one child family. The findings suggest that work insurance programs and professional family support from government and community social workers may be beneficial to improve the quality of life for younger parents.

\section{Abbreviations}

PROMIS, Patient-Reported Outcomes Measurement Information System; SPSS, Statistical Package for the Social Sciences; B, Nonstandardized coefficients; SE, standard error; Beta, Standardized coefficients

\section{Declarations}

\section{Ethical approvaland consent to participate}

The study was approvedby the local ethics committees of Peking University Medical Ethics Board. All participants gave electronic consent after being informed to the aim of the survey and their rights to refuse to participate.

\section{Consent for publication}

Not applicable

\section{Availability of data and materials}

The datasets used and/or analyzed during the current study are available from the corresponding author on reasonable request.

\section{Competing interests}

No potential conflict of interest was reported by the author(s).

\section{Funding:}

This study was supported by the National Social Science Fund of China [20VYJ042]

\section{Authors' contributions:}


$\mathrm{XHL}$ analyzed and interpreted the data, and wrote the first draft of the manuscript. YSB and NH commented and revised the manuscript. JG conceptualized the study design, supervised the work and revised the manuscript. All authors read and approved the final manuscript.

\section{Acknowledgements}

Not applicable.

\section{References}

1. Zhu N, Zhang D, Wang W, Li X, Yang B, Song J, et al. A Novel Coronavirus from Patients with Pneumonia in China, 2019. N Engl J Med. 2020;382(8):727-33.

2. Wilder-Smith A, Freedman DO. Isolation, quarantine, social distancing and community containment: Pivotal role for old-style public health measures in the novel coronavirus (2019-nCoV) outbreak. J Travel Med. 2020;27(2):1-4.

3. Zhang Y, Ma ZF. Impact of the COVID-19 pandemic on mental health and quality of life among local residents in Liaoning Province, China: A cross-sectional study. Int J Environ Res Public Health. 2020;17(7):2381.

4. Melo-Oliveira ME, Sá-Caputo D, Bachur JA, Paineiras-Domingos LL, Sonza A, Lacerda AC, et al. Reported quality of life in countries with cases of COVID19: a systematic review. Expert Review of Respiratory Medicine. 2020.

5. Power M, Kuyken W. World Health Organization Quality of Life Assessment (WHOQOL): Development and general psychometric properties. Soc Sci Med. 1998;46(12):1569-85.

6. Mazza C, Marchetti D, Ricci E, Fontanesi L, Di Giandomenico S, Verrocchio MC, et al. The COVID-19 lockdown and psychological distress among Italian parents: Influence of parental role, parent personality, and child difficulties. Int J Psychol. 2021;

7. Gilleen J, Santaolalla A, Valdearenas L, Salice C, Fusté M. Impact of the COVID-19 pandemic on the mental health and wellbeing of UK healthcare workers. BJPsych Open. 2021;7(3):1-33.

8. Brown SM, Doom JR, Lechuga-Peña S, Watamura SE, Koppels T. Stress and parenting during the global COVID-19 pandemic. Child Abus Negl. 2020;110(2):104699.

9. Lawson M, Piel MH, Simon M. Child Maltreatment during the COVID-19 Pandemic: Consequences of Parental Job Loss on Psychological and Physical Abuse Towards Children. Child Abus Negl. 2020;110:104709.

10. Masarik AS, Conger RD. Stress and child development: A review of the Family Stress Model. Vol. 13, Current Opinion in Psychology. 2017. p. 85-90.

11. Peltz JS, Daks JS, Rogge RD. Mediators of the association between COVID-19-related stressors and parents' psychological flexibility and inflexibility: The roles of perceived sleep quality and energy. J Context Behav Sci. 2020;17:168-76.

12. Marta E, Alfieri S. Family Conflicts. In: Michalos AC, editor. Encyclopedia of Quality of Life and Well-Being Research. Dordrecht: Springer Netherlands; 2014. p. 2164-7.

13. Pietromonaco PR, Beck LA. Adult attachment and physical health. Vol. 25, Current Opinion in Psychology. 2019. p. 115-20.

14. Prime $H$, Wade M, Browne DT. Risk and resilience in family well-being during the COVID-19 pandemic. Am Psychol. 2020;75(5):631-643.

15. Wu M, Xu W, Yao Y, Zhang L, Guo L, Fan J, et al. Mental health status of students' parents during COVID-19 pandemic and its influence factors. Gen Psychiatry. 2020;33(4):1-9.

16. Nordenmark M. Multiple social roles and well-being: A longitudinal test of the role stress theory and the role expansion theory. Acta Sociol. 2004;47(2):115-26.

17. Reichelt M, Makovi K, Sargsyan A. The impact of COVID-19 on gender inequality in the labor market and gender-role attitudes. Eur Soc. 2021;23(S1):S228-45.

18. Collins C, Landivar LC, Ruppanner L, Scarborough WJ. COVID-19 and the gender gap in work hours. Gender, Work Organ. 2021;28(S1):101-12.

19. Ma S, Sun Z, Xue H. Childcare Needs and Parents' Labor Supply: Evidence from the COVID-19 Lockdown. SSRN Electron J. $2020 ; 1-31$. 
20. Gao Y, Qu Z. 'More Children, More Happiness?': New Evidence from Elderly Parents in China, GLO Discussion Paper, N.366. Global Labor Organization (GLO), Essen. Essen: Global Labor Organization (GLO); 2019.

21. Wu Z, Penning MJ. Children and the Mental Health of Older Adults in China: What Matters? Popul Res Policy Rev [Internet]. 2019;38(1):27-52. Available from: https://doi.org/10.1007/s11113-018-9495-z

22. Steiber N. Reported levels of time-based and strain-based conflict between work and family roles in Europe: A multilevel approach. Soc Indic Res. 2009;93(3):469-88.

23. Hays RD, Bjorner JB, Revicki DA, Spritzer KL, Cella D. Development of physical and mental health summary scores from the patient-reported outcomes measurement information system (PROMIS) global items. Qual Life Res. 2009;18(7):873-80.

24. Griggs TL, Casper WJ, Eby LT. Work, family and community support as predictors of work-family conflict: A study of lowincome workers. J Vocat Behav. 2013;82(1):59-68.

25. Mache S, Bernburg M, Vitzthum K, Groneberg DA, Klapp BF, Danzer G. Managing work-family conflict in the medical profession: working conditions and individual resources as related factors. BMJ Open. 2015;5(4):e006871.

26. Menchaca D, Dehle C. Marital quality and physiological arousal: How do i love thee? Let my heartbeat count the ways. Am J Fam Ther. 2005;33(2):117-30.

27. Choi H, Marks NF. Marital conflict, depressive symptoms, and functional impairment. J Marriage Fam. 2008;70(2):377-90.

28. Reczek C, Zhang Z. Parent-Child Relationships and Parent Psychological Distress: How Do Social Support, Strain, Dissatisfaction, and Equity Matter? Res Aging. 2016;38(7):742-66.

29. Kim E. Intergenerational acculturation conflict and korean american parents' depression symptoms. Issues Ment Health Nurs. 2011;32(11):687-95.

30. Conger KJ, Rueter MA, Conger RD. The Role of Economic Pressure in the Lives of Parents and Their Adolescents: The Family Stress Model. In: Negotiating Adolescence in Times of Social Change. New York, NY, US: Cambridge University Press; 2010. p. 201-23.

31. Papp LM, Cummings EM, Goeke-Morey MC. For richer, for poorer: Money as a topic of marital conflict in the home. Fam Relat. 2009;58(1):91-103.

32. Whiston SC, Cinamon RG. The work-family interface: Integrating research and career counseling practice. Career Dev Q. 2015;63(1):44-56.

33. Benzeval M, Burton J, Crossley TF, Fisher P, Jäckle A, Perelli-Harris B WS. Understanding Society COVID-19 Survey May Briefing Note: Family relationships,. Understanding Society at the Institute for Social and Economic Research; 2020. (Understanding Society Working Paper Series).

34. Liu B, Chen H, Yang X, Hou C. Why Work Overtime? A Systematic Review on the Evolutionary Trend and Influencing Factors of Work Hours in China. Front Public Heal. 2019;7:343.

35. Venkatesh V. Impacts of COVID-19: A research agenda to support people in their fight. Int J Inf Manage. 2020;55:102197.

36. Yang W, Yan F. The annihilation of femininity in mao's China: Gender inequality of Sent-Down youth during the cultural revolution. China Inf. 2017;31(1):63-83.

37. Grzywacz JG, Marks NF. Reconceptualizing the work-family interface: an ecological perspective on the correlates of positive and negative spillover between work and family. J Occup Health Psychol. 2000;5(1):111-26.

38. Kwon HK, Rueter MA, Lee MS, Koh S, Ok SW. Marital relationships following the Korean economic crisis: Applying the family stress model. J Marriage Fam. 2003;65(2):316-25.

39. Kim J. Workplace Flexibility and Parent-Child Interactions Among Working Parents in the U.S. Soc Indic Res. 2020;151(2):427-69.

40. Meraviglia C, Dudka A. The gendered division of unpaid labor during the Covid-19 crisis: did anything change? Evidence from Italy. Int J Sociol. 2021;51(1):64-75.

41. Blake J. Family size and the quality of children. Demography. 1981;18(4):421-42.

42. Ward RA, Spitze G, Deane G. The more the merrier? Multiple parent-adult child relations. J Marriage Fam. 2009;71(1):161-73.

43. Voydanoff P. Toward a conceptualization of perceived work-family fit and balance: A demands and resources approach. $J$ Marriage Fam. 2005;67(4):822-36. 
44. Dillon L, Beechler M. Marital satisfaction and the impact of children in collectivist cultures: A meta-analysis. J Evol Psychol. 2010;8(1):7-22.

45. Liu H. The quality-quantity trade-off: Evidence from the relaxation of China's one-child policy. J Popul Econ. 2014;27(2):565602.

46. Argys LM, Averett SL. The effect of family size on education: New evidence from China's one-child policy. J Demogr Econ. 2019;85(1):21-42.

\section{Figures}

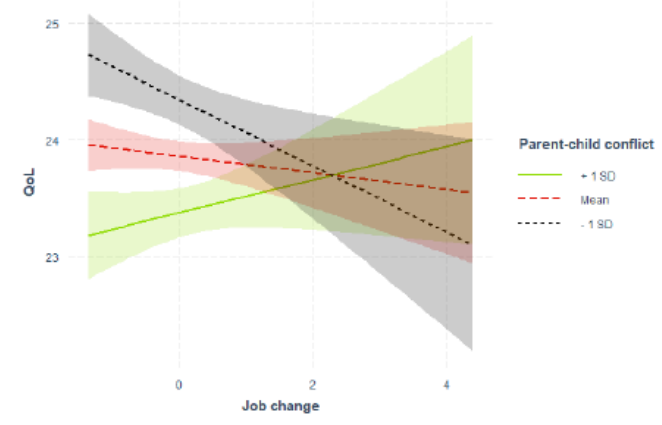

A Whole sample

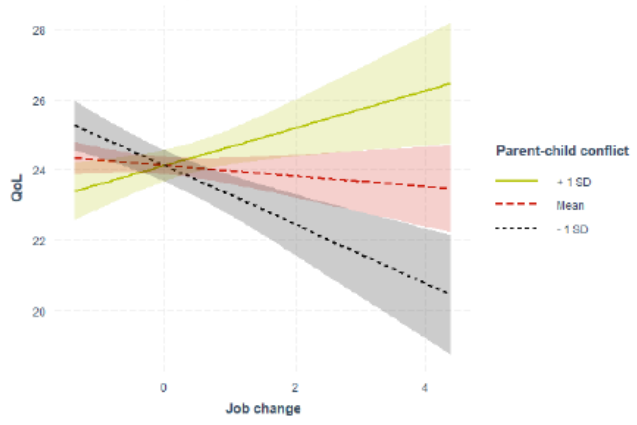

C Male sample

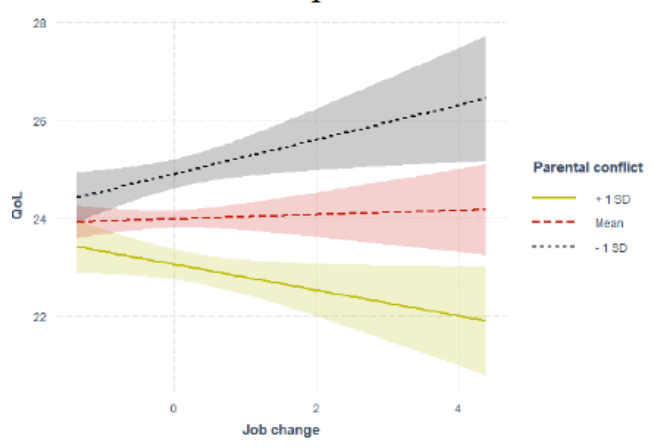

E One child family

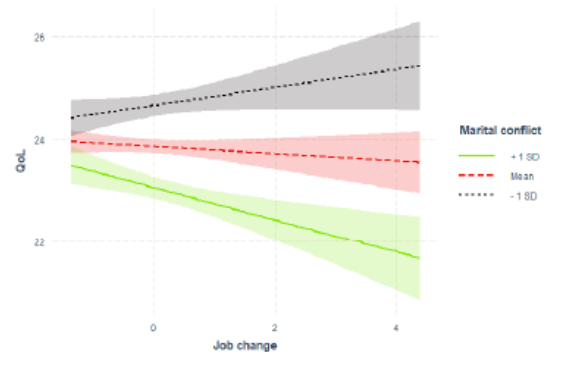

B Whole sample

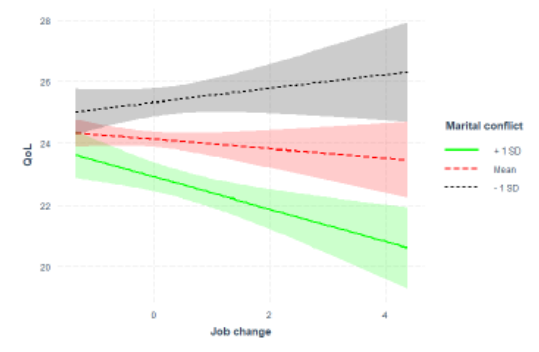

D Male sample

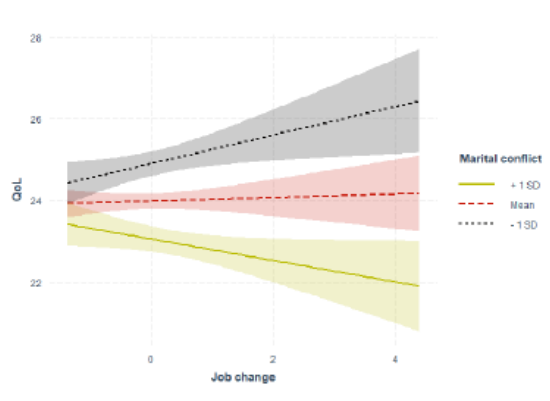

F One child family

\section{Figure 1}

Interaction effect of job change and family conflict on QoL

\section{Supplementary Files}

This is a list of supplementary files associated with this preprint. Click to download. 
- Attachment.docx

Page 13/13 